\title{
Sequential sampling of Euschistus heros (Heteroptera: Pentatomidae) in soybean
}

\author{
Leandro Aparecido de Souza ${ }^{1}$, José Carlos Barbosa ${ }^{2 *}$, José Fernando Jurca Grigolli ${ }^{1}$ Diego Felisbino Fraga ${ }^{1}$, Lílian Cristina \\ Moraes $^{2}$, Antonio Carlos Busoli ${ }^{1}$
}

\begin{abstract}
'São Paulo State University/FCAV - Dept. of Phytosanitary, Via de Acesso Prof. Paulo Donato Castellane s/n - 14884 900 - Jaboticabal, SP - Brazil.

${ }^{2}$ São Paulo State University/FCAV - Dept. of Exact Science. *Corresponding author <jcbarbosa@fcav.unesp.br>
\end{abstract}

Edited by: Richard V. Glatz
ABSTRACT: Integrated pest management programs for soybean (Glycine max (L.) Merrill) must be based on efficient sampling plans for estimating the pest population. Based on the spatial distribution of the Neotropical brown stink bug Euschistus heros (Fabricius, 1794) found on soybean, it was possible to construct a sequential sampling plan for the survey of this insect found on soybean. The experiment was carried out during two growing seasons, 2010/2011 and 2011/2012, using the transgenic soybean cultivar M 7908 RR, in plots of $10,000 \mathrm{~m}^{2}$ subdivided into 100 plots of $100 \mathrm{~m}^{2}(10 \mathrm{~m} \times 10 \mathrm{~m})$. Nymphs $>0.5 \mathrm{~cm}$ (4 $4^{\text {th }}$ and $5^{\text {th }}$ instars) plus adults were counted weekly from five drop cloth technique samplings per plot. To evaluate insect dispersion in the area, the following indices were used: variance/mean ratio, Morisita's index, Green's coefficient, the $k$ exponent of the negative binomial distribution, and estimation of the common exponent $k(k c)$. To study probabilistic models to describe the spatial distribution of the insects, adjustments of the Poisson and negative binomial distributions were tested. Two sequential sampling plans for separate fields, one for grain production and the other for seed production, were prepared. The data fitted a negative binomial distribution and a sampling plan was drawn up using the sequential likelihood ratio test (SLRT). The maximum sampling unit number expected for control-related decision making was six in grain production fields, and nine in seed production fields.

Keywords: Neotropical brown stink bug, sampling method
Received September 23, 2013

Accepted July 01, 2014 to whether the results should be accepted or rejected, or whether sampling should be continued (Barbosa, 1992). This study aimed to establish a sequential sampling plan for $E$. heros in soybean.

\section{Materials and Methods}

The experiment was carried out in Jaboticabal, in the state of São Paulo, Brazil (21 ${ }^{\circ} 14^{\prime} 05^{\prime \prime}$ S 048 17'09" W; $615 \mathrm{~m}$ a.s.l.), for two growing seasons, 2010/2011 and 2011/2012. The soybean cultivar M 7908 RR (transgenic with tolerance to the herbicide glyphosate), which is an early-maturing cultivar, was used. Seeds were sown on Nov 24 $4^{\text {th }} 2010$, and plants emerged on Nov $29^{\text {th }} 2010$. For the second cropping season, seeds were sown on Nov $21^{\text {st }} 2011$, emerging on Nov $26^{\text {th }} 2011$, when the applications of herbicide (Fomesafen + Fluazifop-p-butyl) and fungicide (azoxistrobina + ciproconazole) were administered. In both growing seasons, a commercial soybean field of 30 ha in area was chosen, in which a $10,000 \mathrm{~m}^{2}$ area was defined and then subdivided into 100 plots of $100 \mathrm{~m}^{2}$ each $(10 \times 10 \mathrm{~m})$. Each plot was considered a sampling unit. The soybean was planted in 45-cm plant spacing, making 330,000 plants in total. Insecticides were not sprayed during the experiment to avoid any interference with the entomofauna.

Weekly samplings were conducted from day 86 on to day 115 after plant emergence (DAE), which corresponded to the early stages of seed filling (R5) to full maturity (R8) (Fehr and Caviness, 1977). Five sampling points per unit $\left(100 \mathrm{~m}^{2}\right)$ were randomly assessed using the drop cloth technique, which is a method requiring a 
white piece of cloth or plastic, $1 \mathrm{~m}$ in length and $0.5 \mathrm{~m}$ in width, to be attached to two wooden sticks that are placed in between two rows of soybean plants. Plants should be shaken so that the pests will fall down onto the cloth. Accordingly, 30 plants were sampled, since each row of plants contained approximately 15 plants. At each sampling point, the number of nymphs $>0.5$ $\mathrm{cm}\left(4^{\text {th }}\right.$ and $5^{\text {th }}$ instars $)$ plus adults was recorded since soybean seeds are susceptible to injury and damage caused during these stages of insect development, which in turn inform decisions on the application of pesticides (Hoffmann-Campo et al., 2000).

For data analysis, the average values and variance in the number of nymphs $>0.5 \mathrm{~cm}$ plus adults per plot were recorded for each sampling period. The dispersion indices for determining the degree of aggregation of $E$. heros were calculated, as follows:

Variance/mean ratio (I): The variance/mean ratio, also called the dispersion index $\left(\mathrm{I}=\mathrm{s}^{2} \mathrm{~m}^{-1}\right)$, is commonly used to measure the deviation of an arrangement in random conditions, in which $\mathrm{I}=1$ indicates a random spatial distribution; I < 1 uniform distribution; and I > 1 aggregated distribution (Rabinovich, 1980). The distance of randomness can be tested by using the chi-square test, with $n$-1 degrees of freedom $\left[\chi^{2}=(n-1) \mathrm{s}^{2} \mathrm{~m}^{-1}\right]$ (Elliott, 1979).

Morisita's index (Id): This index is independent of the size of the sampling unit (Morisita, 1962). This index is given by the equation:

$$
I d=n \frac{\sum[x(x-1)]}{\sum x\left(\sum x-1\right)}=n \frac{\sum x^{2}-\sum x}{\left(\sum x\right)^{2}-\sum x}
$$

where: $n=$ number of sample units; $x=$ number of nymphs or adults per plot.

The Morisita's index is equal to one for random distributions; greater than one for contagious distributions; and lower than one for regular or uniform distributions. Departure from randomness can be tested by:

$X_{d}^{2}=I_{d}\left(\sum x_{i}-1\right)+n-\sum x_{i} \sim \chi_{(n-1)}^{2}$ rejected.

If $X_{d}^{2} \geq \chi_{(n-1, g, l . ; 0,05)}^{2}$ the hypothesis of randomness is

Green's coefficient (Cx): The Green coefficient is generally used for describing different types of patterns. Negative values indicate a uniform distribution pattern, whereas positive values indicate an aggregate pattern (Green, 1966). It is based on the variance/mean ratio and is given by:

$C_{x}=\frac{\left(s^{2} / \hat{m}\right)-1}{\sum_{i=1}^{n} x_{i}-1}$ where: $s^{2}=$ sampling variance; $m=$ sampling mean; $x_{i}$ $=$ number of nymphs or adults per plot.

The $k$ exponent for negative binomial distribution $(\boldsymbol{k})$ : This index is an indicator of arthropod aggregation, and should only be used when the data fit the negative binomial distribution (Elliott, 1979). Negative values indicate a uniform distribution, low and positive values 10 $<k<2$ ) indicate a highly aggregated distribution, values ranging from 2 to 8 indicate a moderate aggregation, and values greater than 8 indicate a random distribution (Costa et al., 2010). Firstly, $k$ values were obtained by the moment's method, which is given by:

$k=\frac{m^{2}}{s^{2}-m}$,

and later by the maximum likelihood method:

$N \ln \left(1+\frac{\hat{m}}{\hat{k}}\right)=\sum_{i=1}^{n c}\left(\frac{A\left(x_{i}\right)}{\hat{k}+x_{i}}\right)$

where: $N=$ number of sampling units; $A\left(x_{i}\right)=$ sum of frequencies of values greater than $x_{i} ; n_{c}=$ number of classes in the frequency distribution; and $x_{i}=$ number of nymphs $>0.5 \mathrm{~cm}$ plus adults per plot.

Estimation of the common exponent $\boldsymbol{k}(\boldsymbol{k} \boldsymbol{c})$ : To determine a common value of $k$ that represented most of the sampling period, we used the method proposed by Bliss and Owen (1958), known as the "method of weighted regression". To calculate $k c$ of number of nymphs $>0.5 \mathrm{~cm}\left(4^{\text {th }}\right.$ and $5^{\text {th }}$ instars $)$ plus adults, the samples from two growing seasons were analyzed together.

Probabilistic models for studying the spatial distribution of pests: In each sample, the adjustment of the Poisson and negative binomial distributions was tested. The model shows good adjustment to the original data when the observed and expected frequencies are close. This proximity was tested by the chi-square test, given by:

$X^{2}=\sum_{i=1}^{n_{c}} \frac{\left(F O_{i}-F E_{i}\right)^{2}}{F E_{i}}$,

where: $F O_{i}=$ observed frequency in class $i_{;} F E_{i}=$ expected frequency in class $i_{i} n_{c}=$ number of classes in the frequency distribution. by:

The number of degrees of freedom of $\chi^{2}$ is given

$v=n_{c}-n_{p}-1$,

where $n_{c}=$ number of classes in the frequency distribution and $n_{p}=$ number of parameters estimated in the sample. 
Poisson distribution: The Poisson distribution best represents the random spatial distribution of insects and is characterized by presenting the variance equal to the average $\left(\sigma^{2}=\mu\right)$ (Southwood, 1978). The equations for calculating the probabilities are given by:

$$
P_{(x)}=\frac{\lambda^{x} e^{-\lambda}}{x !}
$$

where: $\mathrm{P}(\mathrm{x})=$ probability of occurring $\mathrm{x}$ individuals in the sampling unit; $\lambda=$ parameter of the distribution $(\lambda$ $=\mu=\sigma^{2}$; ; and $\mathrm{e}=$ base of the natural logarithm.

Negative binomial distribution: This index presents the variance as being greater than the average $\left(\sigma^{2}>\mu\right)$ and has two parameters, the average $(m)$ and the exponent $k(k>0)$ (Taylor, 1984). The series of probabilities can be calculated for a sampling by using the following equation:

$P(x)=\frac{P(x-1) \cdot R \cdot(k+x-1)}{x}, x=1,2,3, \ldots$,

in which:

$$
P(0)=\left(1+\frac{m}{k}\right)^{-k}
$$

where: $m=$ sampling mean; $k=$ exponent of the negative binomial distribution; $P_{(x)}=$ probability of occurring $x$ individuals in the sampling unit.

The plan was based on the sequential likelihood ratio test (SLRT) proposed by Wald (1945). The plan is to test with the lowest expected number of samples possible in the hypothesis: $H_{0}: m=m_{0}$ vs. $H_{1}: m=$ $m_{1}$, where $m$ represents the means and $\mathrm{m}_{1}>\mathrm{m}_{0}$. The rejection of $\mathrm{H}_{0}$ indicates the need to apply pest control methods, while acceptance of $\mathrm{H}_{0}$ means that control is not required (Allen et al., 1972).

The decision straight line equations, which determine whether control is required or not, are called $S_{1}$ and $S_{0}$ and are represented by $S_{1}=h_{1}+$ an and $S_{0}=h_{0}$ $+a n$, in which $n$ indicates the number of sample units to be used, $h_{0}$ and $h_{1}$ values are the linear coefficients, and $a$ is the angular coefficient.

Two sequential sampling plans were devised, one for fields of grain and the other for fields used for seed production. For the fields of grain, the control level $\left(\mathrm{m}_{1}\right)$ at 4.0 nymphs $>0.5 \mathrm{~cm}$ plus adults per drop cloth sampling and the security level $\left(\mathrm{m}_{0}\right)$ was set at 1.5 nymph $>0.5 \mathrm{~cm}$ plus adults, based on the hypothesis $\mathrm{H}_{0}: \mathrm{m}_{0}=$ 1.5 versus $\mathrm{H}_{1}: \mathrm{m}_{1}=4.0$, and for fields for seed production the control level $\left(\mathrm{m}_{1}\right)$ was set at 2.0 nymphs $>0.5$ $\mathrm{cm}$ plus adults per drop cloth sampling. The security level $\left(\mathrm{m}_{0}\right)$ was set at 0.75 nymphs $>0.5$ plus adults based on the hypothesis $\mathrm{H}_{0}: \mathrm{m}_{0}=0.75$ versus $\mathrm{H}_{1}: \mathrm{m}_{1}$ $=2.0$.

The control level $\left(\mathrm{m}_{1}\right)$ was used in this experiment (Hoffmann-Campo et al., 2000) and the security level $\left(\mathrm{m}_{0}\right)$ was obtained based on the lowest average found in sampling periods (lower limit) from the seed production field. In the field of grain production, this value was doubled since the level of control was also duplicated. Type I and II errors were determined as $\alpha$ $=\beta=0.05$ which is the most suitable for studies involving insects (Young and Young, 1998).

The values of $h_{0}, h_{1}$ and $\alpha$ were determined according to the type of spatial distribution of the pest, in this case based on the negative binomial model, using the equations below (Young and Young, 1998):

$h_{0}=\frac{\ln \left(\frac{\beta}{1-\alpha}\right)}{\ln \left[\frac{m_{1}\left(m_{0}+k\right)}{m_{0}\left(m_{1}+k\right)}\right]}$

$h_{1}=\frac{\ln \left(\frac{1-\beta}{\alpha}\right)}{\ln \left[\frac{m_{1\left(m_{0}+k\right)}}{m_{0}\left(m_{1}+k\right)}\right]}$

$a=k \frac{\ln \left(\frac{m_{1}+k}{m_{0}+k}\right)}{\ln \left[\frac{m_{1}\left(m_{0}+k\right)}{m_{0}\left(m_{1}+k\right)}\right]}$

where: $m_{0}=$ security level; $m_{1}=$ control level; $\alpha=$ type I error; $\beta=$ type II error; $h=$ auxiliary variable dependent $p ; a=$ angular coefficient; $k=$ index $k c(\mathrm{Com}-$ mon $k$ ) calculated by the method proposed by Bliss and Owen (1958).

The test consisted of:

a) Rejection of $\mathrm{H}_{0}$ when the sample size was $\mathrm{N}^{*}$ such that:

$a N+h_{0}<S<a N+h_{1}$, for $\mathrm{N}=1,2 \ldots \mathrm{N}^{*}-1$, and

$S \geq a N^{*}+h_{1}$

b) Acceptance of $\mathrm{H}_{0}$ when the sample size was $\mathrm{N}^{*}$, such that:

$a N+h_{0}<S<a N+h_{1}$, for $\mathrm{N}=1,2, \ldots, \mathrm{N}^{*}-1$, and

$S \leq a N^{*}+h_{0}$

where: $\mathrm{N}=$ number of sampling units to be used; $\mathrm{S}=$ sum of countings.

In summary, assuming a system of two orthogonal axes, and plotting $\mathrm{S}$ against the ordinates and $\mathrm{N}$ on the abscissas, sampling is successively continued until the value of $\mathrm{S}$ is located above or on the straight line $\left(\alpha N^{*}+h_{1}\right) \mathrm{aN}^{*}+\mathrm{h}_{1}$, when $\mathrm{H}_{0}$ is rejected; below or on the straight line $\left(\alpha N^{*}+h_{0}\right)$, when $\mathrm{H}_{0}$ is accepted. 
In addition to the straight lines, it is convenient to express the characteristic operation curve $O C(\mathrm{~m})$, which provides the probability of accepting $\mathrm{H}_{0}$ as a function of the mean $\mathrm{m}$ for pre-established values of $\alpha$ and $\beta$. In the deduction, Wald (1945) used an auxiliary variable $h$ depending on $m$, resulting in:

$$
\begin{aligned}
& O C(m)=\frac{[(1-\beta) / \alpha]^{h}-1}{[(1-\beta) / \alpha]^{h}-[\beta /(1-\alpha)]^{h}}, h \neq 0 \\
& O C(m)=\frac{\ln [(1-\beta) / \alpha]}{\ln [(1-\beta) / \alpha]-\ln [\beta /(1-\alpha)]}, h=0, m=a
\end{aligned}
$$

where: $\alpha=$ type I error; $\beta=$ type II error; $h=$ auxiliary variable dependent $p ; m=$ average; $a=$ angular coefficient.

In the negative binomial distributions with $\mathrm{k}$ in common, the ratio between $h$ and $m$ is given by:

$$
\frac{m}{k_{c}}=\frac{1-\left(q_{0} / q_{1}\right)^{h}}{\left[\left(p_{1} q_{0}\right) /\left(p_{0} q_{1}\right)\right]^{h}-1}, h \neq 0 .
$$

where: $k=$ exponent $k$ of the negative binomial distribution; $h=$ auxiliary variable dependent $\mathrm{p} ; m=$ average.

This relationship allows for expressing $O C(m)$ as a function of $m$, arbitrating $h$, where $k=$ exponent $k$ of the negative binomial distribution obtained by the maximum likelihood method or the method of moments;

$p_{0}=\mathrm{m}_{0} / \mathrm{k} ; p_{1}=\mathrm{m}_{1} / \mathrm{k} ; q_{0}=1+\mathrm{p}_{0} ; q_{1}=1+\mathrm{p}_{1}$.

The curve of the expected size $E[N]$ that provides the mean expected sample size for the decision to accept or reject $H_{0}$ was calculated for the plan by the expression (Young and Young, 1998):

$$
E[N]=\frac{b_{1}+\left(b_{0}-b_{1}\right) \cdot O C(m)}{m-a}, h \neq 0 .
$$

where: $h=$ auxiliary variable dependent $\mathrm{p} ; m=$ average; $a=$ angular coefficient.

By using this function, the expected number of samples can be expressed as a function of $m$. On the other hand, if in practice it is desirable to fix the sample size, the maximum expected value is recommended for $E[N]$, in the corresponding SLRT.

\section{Results and Discussion}

Values for the spatial distribution of nymphs > $0.5 \mathrm{~cm}$ plus adults of $E$. heros for both cropping seasons were greater than one for the variance/mean ratio (I) on six sampling dates, where values were close to one on the other four dates. Thus, the distribution pattern of the pest ranged from moderately aggregated to random (Table 1). Values for Morisita's index (Id) are in accordance with those obtained for the variance/mean ratio (Table 1).

Green's coefficient $(C x)$ values were positive for all sampling dates and in both cropping seasons (Table 1), indicating aggregated distribution of the pest's population (Green, 1966). Values for the exponent of negative binomial distribution $(k)$, estimated using the maximum likelihood method, ranged from 0 to 2, which indicates an aggregated pattern; values higher than eight indicate a random distribution (Costa et al., 2010). Immature forms of Nezara viridula (L.) and Piezodorus guildinii (Westw.) at their late stages of development (fourth and fifth instars) are the most important stages for the dispersion of these species in the field (Panizzi et al., 1980).

Initially, data were tested to observe whether they fitted a Poisson distribution; later, since the means were lower than the variances for most of the sampling periods, we tested the data to see if they fitted the negative binomial distribution. Sampling periods demonstrated that their distribution is not random, when chi-square test values were significant at $1 \%$ (114 DAE in growing season $2010 / 2011$ and 115 DAE in growing season 2011/2012) or $5 \%$ probability (94 DAE in growing season 2011/2012) when fitting Poisson's distribution, (Table 2). When we attempted to fit the sampling periods to the negative binomial distribution, the values were non-significant and lower than the Poisson distribution, confirming that the spatial distribution was aggregated (Table 2).

As the test of adhesion of the observed frequencies showed a good fit to the negative binomial distribution, the option was to set this type of distribution with a common $k(k c)$ which represented the majority of samples. The chi-square value of $k c$ was significant and in the analysis of variance, the $\mathrm{F}$ test for inclination $(1 / k)$ was significant and non-significant for intersection, which met the necessary conditions for obtaining a common $k$ according to Bliss and Owen (1958) (Table 3).

To establish a sequential sampling plan we calculated the equations for $\mathrm{S}_{0}$ and $\mathrm{S}_{1}$ for each $\mathrm{N}$ value, so that the decision lines of the sequential sampling plan, superior and inferior, could be obtained (Figures 1 and 2). In the sequential sampling plan (Figures 1 and 2), samples were obtained by using a drop cloth technique randomly throughout the field, and the number of stinkbugs was recorded. Numbers were counted and accumulated after each sampling, and these values were compared with threshold values on the graph (upper and lower). Where the total accumulated value was below the lower line (lower limit), sampling should be stopped and $\mathrm{H}_{0}$ accepted, deciding against pest control. Where the total cumulative value was above the upper straight line (upper limit), sampling should be interrupted, $\mathrm{H}_{0}$ rejected, and pest control undertaken. If the accumulated value was between the two lines, sampling should be continued until reaching the expected maximum number of samples for decision making. 
Table 1 - Means, variances, and dispersion indices for the number of nymphs larger than $0.5 \mathrm{~cm}$ plus adults of Euschistus heros in soybean. Jaboticabal - SP, Brazil, in the growing seasons 2010/2011 and 2011/2012.

\begin{tabular}{|c|c|c|c|c|c|c|}
\hline \multirow{2}{*}{ Growing seasons } & \multirow{2}{*}{ Index } & \multicolumn{5}{|c|}{ Sampling period } \\
\hline & & 86 DAE & 93 DAE & 100 DAE & $107 \mathrm{DAE}$ & $114 \mathrm{DAE}$ \\
\hline \multirow{10}{*}{$2010 / 2011$} & $m$ & 0.8200 & 1.3500 & 1.6100 & 1.9500 & 1.6500 \\
\hline & $s^{2}$ & 0.6339 & 1.3005 & 1.5332 & 1.8662 & 2.8965 \\
\hline & $I=s^{2} m^{-1}$ & 0.7730 & 0.9633 & 0.9523 & 0.9570 & 1.7554 \\
\hline & ld & 0.7227 & 0.9729 & 0.9705 & 0.9781 & 1.4560 \\
\hline & $X^{2} \mathrm{ld}$ & $76.5366^{\mathrm{NS}}$ & $95.3704^{\text {NS }}$ & $94.2795^{N S}$ & $94.7436^{\mathrm{NS}}$ & $173.7879^{* *}$ \\
\hline & $C x$ & 0.0028 & 0.0002 & 0.0002 & 0.0002 & 0.0046 \\
\hline & k mom & - & - & - & - & 2.1842 \\
\hline & $k$ max.ver & - & - & - & - & 2.4596 \\
\hline & \multirow{2}{*}{ Index } & \multicolumn{5}{|c|}{ Sampling period } \\
\hline & & $87 \mathrm{DAE}$ & $94 \mathrm{DAE}$ & $101 \mathrm{DAE}$ & $108 \mathrm{DAE}$ & $115 \mathrm{DAE}$ \\
\hline \multirow{8}{*}{ 2011/2012 } & $m$ & 1.0100 & 1.5000 & 1.6500 & 3.2800 & 5.0400 \\
\hline & $s^{2}$ & 1.1413 & 2.3737 & 2.7551 & 4.3451 & 12.1196 \\
\hline & $I=s^{2} m^{-1}$ & 1.1300 & 1.5824 & 1.6697 & 1.3247 & 2.4046 \\
\hline & Id & 1.1287 & 1.3870 & 1.4043 & 1.0983 & 1.2765 \\
\hline & $X^{2} I d$ & $111.8713^{\mathrm{NS}}$ & $156.6667^{* *}$ & 165.3030 ** & $131.1463^{*}$ & $238.0635^{* *}$ \\
\hline & $C x$ & 0.0013 & 0.0039 & 0.0040 & 0.0009 & 0.0027 \\
\hline & k mom & 7.7685 & 2.5751 & 2.4671 & 10.1013 & 3.5880 \\
\hline & $k$ max.ver & 8.5698 & 2.4567 & 2.8699 & 11.2345 & 3.3567 \\
\hline
\end{tabular}

$m=$ sample mean; $s^{2}=$ sample variance; $I$ = variance to mean ratio; Id = Morisita's index; $X^{2} I d=$ distance of randomness test for the Id; $C x=$ Green coefficient; $k$ mom $=k$ by the method of moments; $k_{\text {máx.ver }}=k$ by the maximum likelihood method; * ${ }^{*}$ Significant at $1 \%$; * Significant at $5 \%$; NSNon-significant; DAE $=$ days after plant emergence.

Table 2 - Chi-square $\left(X^{2}\right)$ test adjusting the Poisson and negative binomial distributions for nymphs larger than $0.5 \mathrm{~cm}$ plus adults of Euschistus heros in soybean. Jaboticabal - SP, Brazil, in the growing seasons 2010/2011 and 2011/2012.

\begin{tabular}{|c|c|c|c|c|c|c|c|}
\hline \multirow{2}{*}{ Growing seasons } & \multirow{2}{*}{ Sampling period } & \multicolumn{3}{|c|}{ Poisson } & \multicolumn{3}{|c|}{ Negative binomial } \\
\hline & & $X^{2}$ & g.l. & $p$ & $X^{2}$ & g.l. & $p$ \\
\hline \multirow{5}{*}{$2010 / 2011$} & $86 \mathrm{DAE}$ & $3.30^{\mathrm{NS}}$ & 2 & 0.1914 & $0.47^{\mathrm{NS}}$ & 1 & 0.4911 \\
\hline & $93 \mathrm{DAE}$ & $2.35^{\mathrm{NS}}$ & 4 & 0.6704 & $2.32^{\mathrm{NS}}$ & 3 & 0.5076 \\
\hline & 100 DAE & $0.70^{\mathrm{NS}}$ & 4 & 0.9512 & $1.25^{\mathrm{NS}}$ & 4 & 0.8682 \\
\hline & 107 DAE & $3.33^{\mathrm{NS}}$ & 5 & 0.6483 & $3.27^{\mathrm{NS}}$ & 4 & 0.5126 \\
\hline & $114 \mathrm{DAE}$ & $17.04^{*}$ & 5 & 0.0044 & $2.30^{\mathrm{NS}}$ & 4 & 0.6799 \\
\hline \multirow{5}{*}{$2011 / 2012$} & $87 \mathrm{DAE}$ & $3.11^{\mathrm{NS}}$ & 3 & 0.3740 & $2.00^{\mathrm{NS}}$ & 2 & 0.3674 \\
\hline & 94 DAE & $12.68^{*}$ & 4 & 0.0129 & $3.87^{\mathrm{NS}}$ & 4 & 0.4231 \\
\hline & 101 DAE & $6.43^{\mathrm{NS}}$ & 4 & 0.1690 & $1.65^{\mathrm{NS}}$ & 4 & 0.7985 \\
\hline & $108 \mathrm{DAE}$ & $6.53^{\mathrm{NS}}$ & 7 & 0.4790 & $4.24^{\mathrm{NS}}$ & 7 & 0.7507 \\
\hline & $115 \mathrm{DAE}$ & $65.70^{* *}$ & 9 & $<0.0001$ & $3.04^{\mathrm{NS}}$ & 8 & 0.9317 \\
\hline
\end{tabular}

$X^{2}=$ Statistic of the chi-square test; g.l. $=$ Number of degrees of freedom for the chi-square test; $p=$ probability level of the chi-square test; * ${ }^{*}$ Significant at $1 \%$;

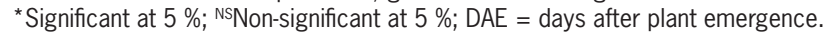

Table 3 - Common $k$ indices for nymphs larger than $0.5 \mathrm{~cm}$ plus adults of Euschistus heros in soybean. Jaboticabal - SP, Brazil, in the growing seasons 2010/2011 and 2011/2012.

\begin{tabular}{|c|c|c|c|}
\hline \multirow[b]{2}{*}{ Kc } & \multicolumn{3}{|c|}{ Homogeneity test's } \\
\hline & $x^{2}$ & $\begin{array}{l}\text { Test F } \\
1 / k\end{array}$ & $\begin{array}{l}\text { Test } \mathrm{F} \\
\text { intersection }\end{array}$ \\
\hline 5.3131 & $27.9120^{* *}$ & $8.9062^{*}$ & $0.9414^{\mathrm{NS}}$ \\
\hline
\end{tabular}

Sampling tables were drawn up (Tables 4 and 5) based on the data provided by the equations for superior $\left(\mathrm{S}_{1}\right)$ and inferior $\left(\mathrm{S}_{0}\right)$ lines to be used in the field, since this is the most practical method to be used in field experiments, according to Fernandes et al. (2003). It is used based on the following steps: (i) when the first counting is performed, the results should be written down in the gap for the first sampling unit; (ii) when the second counting is performed, the results should be added to those obtained previously and written down in the gap for the second sampling unit. This process should be repeated until (i) the total number of stinkbugs is equal to or exceeds the upper threshold, in which case, pest control should be recommended; or (ii) if the total number of stinkbugs is equal to or smaller than the lower threshold, in which case, it is not necessary to control the pest.

The characteristic operating curve, $\mathrm{OC}(\mathrm{m})$, indicates the probability of making a correct decision for a 


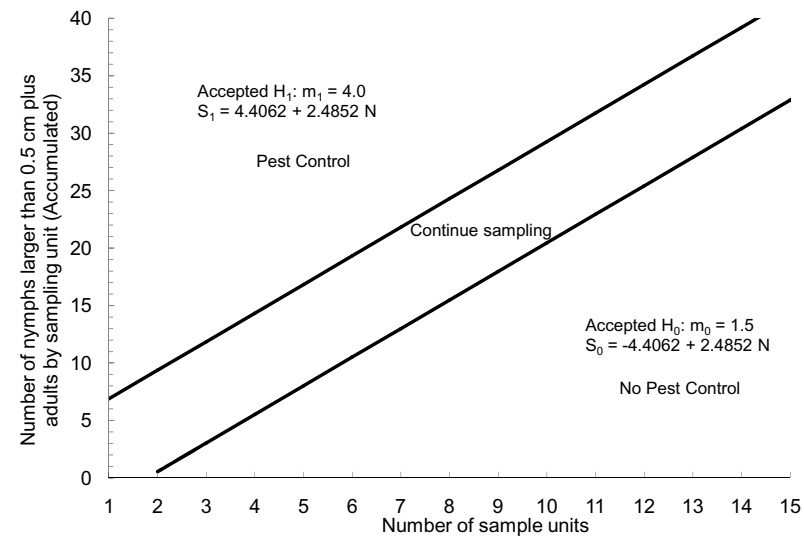

Figure 1 - Decision lines of sequential sampling plan for the number of nymphs larger than $0.5 \mathrm{~cm}$ plus adults of Euschistus heros per sampling unit for grain production field of soybean. Jaboticabal SP, Brazil, in the growing seasons 2010/2011 and 2011/2012.

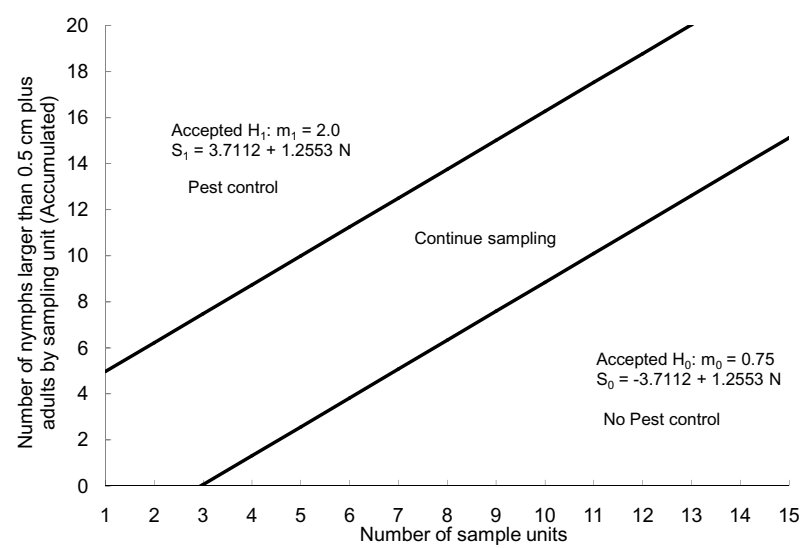

Figure 2 - Decision lines of sequential sampling plan for the number of nymphs larger than $0.5 \mathrm{~cm}$ plus adults of Euschistus heros per sampling unit for seed production fields of soybean. Jaboticabal SP, Brazil in the growing seasons 2010/2011 and 2011/2012.

given level of infestation. When the average is equal to 0.75 nymph $>0.5 \mathrm{~cm}$ plus adults and when the average is equal to 1.5 nymph $>0.5 \mathrm{~cm}$ plus adults of $E$. heros, the test probability of accepting $\mathrm{H}_{0}$ is $95 \%$, recommending no control, and when the average is equal to 2.0 nymphs $>0.5 \mathrm{~cm}$ plus adults and when the average is equal to 4.0 nymphs $>0.5 \mathrm{~cm}$ plus adults of $E$. heros, the probability of accepting $\mathrm{H}_{0}$ is $5 \%$, i.e., the probability of recommending control is $95 \%$ (Figures 3 and 4). Thereafter, the expected number of samples $\mathrm{E}(\mathrm{N})$ was calculated. For the grain production fields, the maximum expected sample size was six sampling units, and for the seed production fields, nine sampling units (Figures 5 and 6), regardless of the size of the area, in homogeneous areas. If this criterion is not met, the area is divided into more homogeneous plots to facilitate the management of these areas.

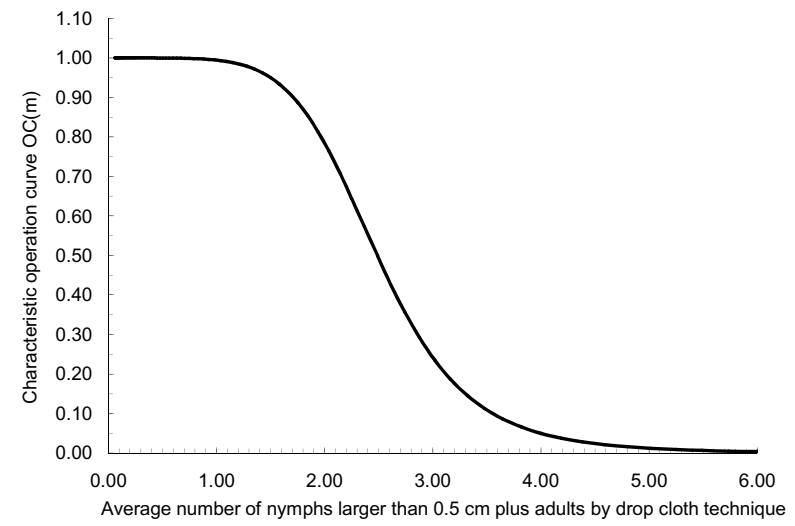

Figure 3 - Characteristic operation curve $\mathrm{OC}(\mathrm{m})$ of the sampling plan for the average number of nymphs larger than $0.5 \mathrm{~cm}$ plus adults of Euschistus heros by the drop cloth technique for grain production fields of soybean. Jaboticabal - SP, Brazil, for the growing seasons 2010/2011 and 2011/2012.

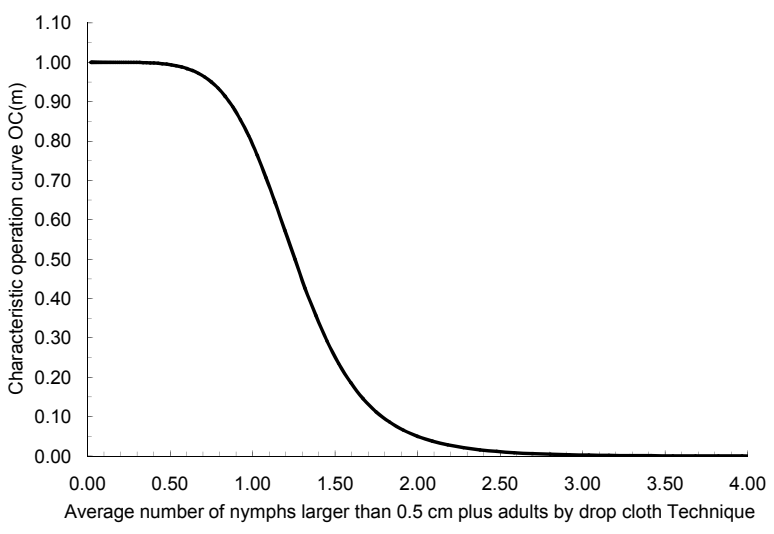

Figure 4 - Characteristic operation curve $O C(m)$ of the sampling plan for the average number of nymphs larger than $0.5 \mathrm{~cm}$ plus adults of Euschistus heros by the drop cloth technique for seed production fields of soybean. Jaboticabal - SP, Brazil, for the growing seasons 2010/2011 and 2011/2012.

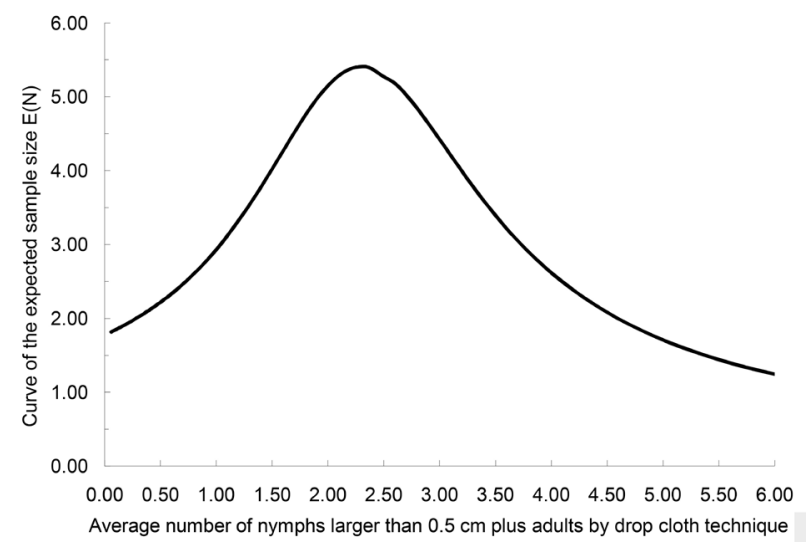

Figure 5 - Curve of the expected sample size $E(N)$ in the sampling sequence for the average number of nymphs larger than $0.5 \mathrm{~cm}$ plus adults of Euschistus heros by the drop cloth technique for grain production fields of soybean. Jaboticabal - SP, Brazil, for the growing seasons 2010/2011 and 2011/2012. 
Table 4 - Sampling of nymphs $>0.5 \mathrm{~cm}$ plus adults of Euschistus heros for grain production fields of soybean. Jaboticabal - SP, Brazil.

\begin{tabular}{|c|c|c|c|}
\hline $\begin{array}{l}\text { Number of } \\
\text { sampling units }\end{array}$ & $\begin{array}{l}\text { Lower limit }\left(\mathrm{S}_{0}\right) \\
\text { (No Pest } \\
\text { Control) }\end{array}$ & $\begin{array}{c}\text { Number of } \\
\text { nymphs }>0.5 \mathrm{~cm} \\
\text { plus adults } \\
\text { (Accumulated) }\end{array}$ & $\begin{array}{l}\text { Superior Limit }\left(\mathrm{S}_{1}\right) \\
\quad \text { (Pest Control) }\end{array}$ \\
\hline 1 & - & & 7 \\
\hline 2 & - & & 10 \\
\hline 3 & 3 & & 12 \\
\hline 4 & 5 & & 15 \\
\hline 5 & 8 & & 17 \\
\hline 6 & 10 & & 20 \\
\hline 7 & 12 & & 22 \\
\hline 8 & 15 & & 25 \\
\hline 9 & 17 & & 27 \\
\hline 10 & 20 & & 30 \\
\hline 11 & 22 & & 32 \\
\hline 12 & 25 & & 35 \\
\hline 13 & 27 & & 37 \\
\hline 14 & 30 & & 40 \\
\hline 15 & 32 & & 42 \\
\hline 16 & 35 & & 45 \\
\hline 17 & 37 & & 47 \\
\hline 18 & 40 & & 50 \\
\hline 19 & 42 & & 52 \\
\hline 20 & 45 & & 55 \\
\hline 21 & 47 & & 57 \\
\hline 22 & 50 & & 60 \\
\hline 23 & 52 & & 62 \\
\hline 24 & 55 & & 65 \\
\hline 25 & 57 & & 67 \\
\hline 26 & 60 & & 70 \\
\hline 27 & 62 & & 72 \\
\hline 28 & 65 & & 74 \\
\hline 29 & 67 & & 77 \\
\hline 30 & 70 & & 79 \\
\hline
\end{tabular}

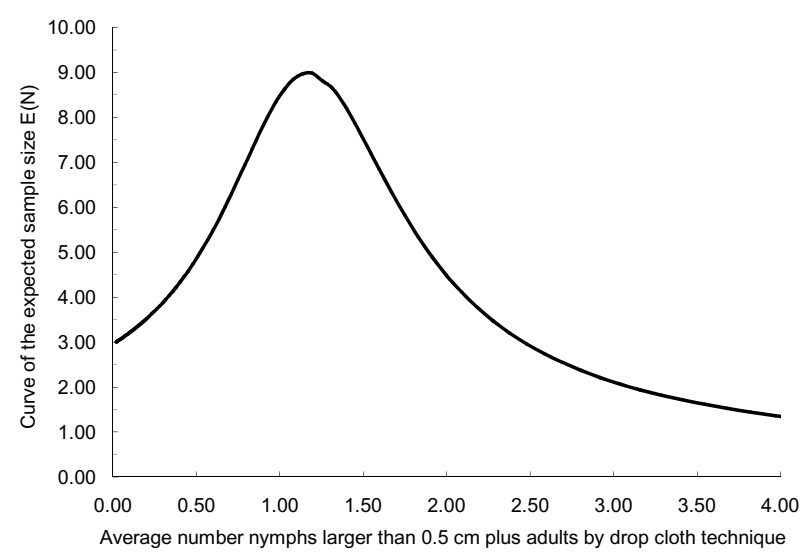

Figure 6 - Curve of the expected sample size $E(N)$ in the sampling sequence for the average number nymphs larger than $0.5 \mathrm{~cm}$ plus adults of Euschistus heros by the drop cloth technique for seed production fields of soybean. Jaboticabal - SP, Brazil, for the growing seasons 2010/2011 and 2011/2012.
Table 5 - Sampling of nymphs $>0.5 \mathrm{~cm}$ plus adults of Euschistus heros for seed production fields of soybean. Jaboticabal - SP, Brazil.

\begin{tabular}{|c|c|c|c|}
\hline $\begin{array}{l}\text { Number of } \\
\text { sampling units }\end{array}$ & $\begin{array}{c}\text { Lower limit }\left(\mathrm{S}_{0}\right) \\
\text { (No Pest } \\
\text { Control) }\end{array}$ & $\begin{array}{c}\text { Number of } \\
\text { nymphs }>0.5 \mathrm{~cm} \\
\text { plus adults } \\
\text { (Accumulated) }\end{array}$ & $\begin{array}{l}\text { Superior Limit }\left(\mathrm{S}_{1}\right) \\
\text { (Pest Control) }\end{array}$ \\
\hline 1 & - & & 5 \\
\hline 2 & - & & 7 \\
\hline 3 & - & & 8 \\
\hline 4 & 1 & & 9 \\
\hline 5 & 2 & & 10 \\
\hline 6 & 3 & & 12 \\
\hline 7 & 5 & & 13 \\
\hline 8 & 6 & & 14 \\
\hline 9 & 7 & & 15 \\
\hline 10 & 8 & & 17 \\
\hline 11 & 10 & & 18 \\
\hline 12 & 11 & & 19 \\
\hline 13 & 12 & & 21 \\
\hline 14 & 13 & & 22 \\
\hline 15 & 15 & & 23 \\
\hline 16 & 16 & & 24 \\
\hline 17 & 17 & & 26 \\
\hline 18 & 18 & & 27 \\
\hline 19 & 20 & & 28 \\
\hline 20 & 21 & & 29 \\
\hline 21 & 22 & & 31 \\
\hline 22 & 23 & & 32 \\
\hline 23 & 25 & & 33 \\
\hline 24 & 26 & & 34 \\
\hline 25 & 27 & & 36 \\
\hline 26 & 28 & & 37 \\
\hline 27 & 30 & & 38 \\
\hline 28 & 31 & & 39 \\
\hline 29 & 32 & & 41 \\
\hline 30 & 33 & & 42 \\
\hline
\end{tabular}

In conventional sampling, for 1-9 ha, six sampling points are required for decision making on the control of E. heros (Gallo et al., 2002). In this study, for grain production fields with average infestations of 1.5 nymph $>0.5 \mathrm{~cm}$ plus adults and 4.0 nymphs $>0.5 \mathrm{~cm}$ plus adults per drop cloth sampling, the expected number of samplings were four and three, respectively, and for seed production fields with average infestation of 0.75 nymphs $>0.5 \mathrm{~cm}$ plus adults and 2.0 nymphs $>0.5 \mathrm{~cm}$ plus adults per drop cloth sampling, the expected number of samplings being seven and five, respectively.

As regards the conventional sampling of cotton (Gossypium hirsutum L.) leafworm Alabama argillacea (Hübner, 1818) (Lepidoptera: Noctuidae), it is necessary to sample 100 cotton plants per hectare in order to make decisions about its control (Busoli et al., 2011). However, for sequential sampling, with an expected number of sampling units for an infestation of two larvae per plant, it is necessary to sample only 10 sam- 
pling units per hectare to make decisions (Fernandes et al., 2003).

The sequential sampling plan proposed in this study resulted in reducing the number of sampling units needed for decision-making for the control of $E$. heros, and, consequently, the time and costs required for a population survey of this species found on soybean.

\section{Acknowledgements}

To the Coordination for the Improvement of Higher Level Personnel (CAPES), for the Master's scholarship of the first author and to the FCAV/UNESP for providing the infrastructure.

\section{References}

Allen, J.; Gonzales, D.; Gokhale, D.V. 1972. Sequential sampling plans for the bollworms, Heliothis zea. Environmental Entomology 1: 771-780.

Barbosa, J.C. 1992. The sequencial sampling = A amostragem sequencial. p. 205-211. In: Fernandes, O.A.; Correia, A.C.B.; Bortoli, S.A., eds. Integrated management of pests and nematodes $=$ Manejo integrado de pragas e nematóides. FUNEP, Jaboticabal, SP, Brazil. (in Portuguese).

Bliss, C.I.; Owen, A.R.G. 1958. Negative binomial distribution with a common K. Biometrika 45: 37-58.

Busoli, A.C.; Grigolli, J.F.J.; Fraga, D.F.; Souza, L.A.; Funichello, M.; Nais, J.; Silva, E.A. 2011. Current status of IPM practices for cotton in the Brazilian Cerrado = Atualidades no MIP algodão no Cerrado Brasileiro. p. 117-138. In: Busoli, A.C.; Fraga, D.F.; Santos, L.C.; Alencar, J.R.C.C.; Grigolli, J.F.J.; Janini, J.C.; Souza, L. A.; Viana, M.V.; Funichello, M., eds. Topics in agricultural entomology IV. Multipress, Jaboticabal, SP, Brazil. (in Portuguese).

Corrêa-Ferreira, B.S.; Azevedo, J. 2002. Soybean seed damage by different species of stink bugs. Agricultural and Forest Entomology 4: 145-150.

Costa, M.G.; Barbosa, J.C.; Yamamoto, P.T.; Leal, R.M. 2010. Spatial distribution of Diaphorina citri Kuwayama (Hemiptera:Psyllidae) in citrus orchards. Scientia Agricola 67: 546-554.

Elliott, J.M. 1979. Some Methods for the Statistical Analysis of Samples of Benthic Invertebrates. Freshwater Biological Association, Ambleside, UK.

Fehr, W.R.; Caviness, C.E. 1977. Stages of Soybean Development. State University of Science and Techonoly, Ames, IO, USA.

Fernandes, M.G.; Busoli, A.C.; Barbosa, J.C. 2003. Sequential sampling of Alabama argillacea (Hübner) (Lepidoptera: Noctuidae) on cotton crop. Neotropical Entomology 32: 117122 (in Portuguese, with abstract in English).
Kogan, M.; Herzog, D.C. 1980. Sampling Methods in Soybean Entomology. Springer, New York, NY, USA.

Gallo, D.; Nakano, O.; Silveira Neto, S.; Carvalho, R.P.L.; Baptista, C.G.; Berti Filho, E.; Parra, J.R.P.; Zucchi, R.A.; Alves, S.B.; Vendramim, J.D.; Marchini, L.C; Lopes, J.R.S.; Omoto, C. 2002. Agricultural Entomology $=$ Entomologia Agrícola. FEALQ, Piracicaba, SP, Brazil. (in Portuguese).

Green, R.H. 1966. Measurement of non-randomness in spatial distributions. Researches on Population Ecology 8: 1-7.

Hoffmann-Campo, C.B.; Moscardi, F.; Corrêa-Ferreira, B.S.; Oliveira, L.J.; Sosa-Gómez, D.R.; Panizzi, A.R.; Corso, I.C.; Gazzoni, D.L.; Oliveira, E.B. 2000. Pests of soybean in Brazil and its integrated management $=$ Pragas da soja no Brasil e seu manejo integrado. EMBRAPA. Disponível em http://ag20. cnptia.embrapa.br/Repositorio/circtec30_000g46xpyyv02wx5o k0iuqaqkbbpq943.pdf

[Accessed Sept 25, 2013] (in Portuguese).

Morisita, M. 1962. Id-index, a measure of dispersion of individuals. Researches on Population Ecology 4: 1-7.

Panizzi, A.R.; Galileo, M.H.M.; Gastal, H.A.O.; Toledo, J.F.F.; Wild, C.H. 1980. Dispersal of Nezara viridula and Piezodorus guildinii nymphs in soybeans. Environmental Entomology 9: 293-297.

Rabinovich, J.E. 1980. Introducción a la Ecologia de Poblaciones Animales = Introdução à Ecologia de Populações de Animais. Editorial Continental, Ciudad de México, México (in Spanish).

Sosa-Gómez, D.R.; Corso, I.C.; Morales, L. 2001. Insecticide resistance to Endosulfan, Monocrotophos and Metamidophos in the neotropical brown stink bug, Euschistus heros (F.). Neotropical Entomology 30: 317-320.

Sosa-Gómez, D.R.; Silva, J.J.; Lopes, N.I.O.; Corso, I.C.; Almeida, A.M.R.; Moraes, G.C.P.; Baur, M.E. 2009. Insecticide susceptibility of Euschistus heros (Heteroptera: Pentatomidae) in Brazil. Journal of Economic Entomology 102: 1209-1216.

Sosa-Gómez, D.R.; Silva, J.J. 2010. Neotropical brown stink bug (Euschistus heros) resistance to Methamidophos in Paraná, Brazil. Pesquisa Agropecuária Brasileira 45: 767-769.

Southwood, T.R.E. 1978. Ecological Methods. John Wiley, New York, NY, USA.

Taylor, L.R. 1961. Aggregation, variance and the mean. Nature 189: 732-735.

Wald, A. 1945. Sequential tests of statistical hypothesis. The Annals of Mathematical Statistics, 16: 117-186.

Young, L.J.; Young, J.H. 1998. Statistical Ecology: A Population Perspective. Kluwer Academic, Boston, MA, USA. 